\title{
Assessment of the potential improvement due to multiple apertures in central receiver systems with secondary concentrators
}

\author{
Mark Schmitz $^{\mathrm{a}, *}$, Peter Schwarzbözl ${ }^{\mathrm{a}}$, Reiner Buck ${ }^{\mathrm{b}}$, Robert Pitz-Paal ${ }^{\mathrm{a}}$ \\ a Deutsches Zentrum für Luft- und Raumfahrt e.V. (DLR), Solar Research, Linder Höhe, 51147 Cologne, Germany \\ ${ }^{\mathrm{b}}$ Deutsches Zentrum für Luft- und Raumfahrt e.V. (DLR), Solar Research, Pfaffenwaldring 38-40, 70569 Stuttgart, Germany
}

Received 9 August 2004; received in revised form 21 January 2005; accepted 11 February 2005

Available online 25 March 2005

Communicated by: Associate Editor Lorin Vant-Hull

\begin{abstract}
When striving for maximum efficiencies in solar thermal central receiver systems (CRS) the use of gas turbines with bottoming cycles is inevitable. Pressurized volumetric receivers have proven their feasibility and good performance, and their integration into gas turbine cycles has been demonstrated. One disadvantage of this system is the necessity to use secondary concentrators. The sunlight has to be concentrated into the relatively small glass windows of the receiver, which leads to a limited view cone. This means that of all the possible heliostat positions around the tower, only those within the ellipse, resulting from the section boundary of the view cone with the ground plane, are usable.

For small systems, for which tower costs are small, the resulting heliostat field layout is similar, with or without secondary concentrator. For large systems, which are more cost-effective, tower costs become significant, and the losses due to atmospheric attenuation and spillage dominate over the cosine losses. Thus, the purely North-oriented fields become increasingly sub-optimal.

This article shall demonstrate at what power levels this problem can be alleviated by not using a single, North-oriented aperture, but up to six apertures - each of them associated with a separate heliostat field.
\end{abstract}

(C) 2005 Elsevier Ltd. All rights reserved.

Keywords: Solar thermal power; Central receiver system; CRS; Gas turbine; Combined cycle; Multiple apertures; Heliostat field; HFLCAL

\section{Introduction}

One approach to come to higher efficiencies in the thermal conversion of sunlight to electricity is to raise

\footnotetext{
* Corresponding author. Fax: +49 220366900.

E-mail address: mark.schmitz@dlr.de (M. Schmitz).
}

the process temperature as in modern combined cycle plants (Fig. 1), with peak efficiencies of $55 \%$ and more. Here the solar energy is used to drive a gas turbine and has to be introduced into the pressurized part of the cycle.

Similar requirements are found in many solar chemistry applications.

Thus, pressurized volumetric receivers were developed (Karni et al., 1997; Buck et al., 2000) and tested 


\begin{tabular}{|c|c|c|}
\hline \multicolumn{3}{|l|}{ Nomenclature } \\
\hline $\begin{array}{l}A_{\text {in }}, A_{\text {out }} \text { area of entry, respectively outlet aperture of } \\
\text { a CPC }\left[\mathrm{m}^{2}\right] ; \text { the entry apertures form the tar- }\end{array}$ & & $\begin{array}{l}\text { radiation passing through } A_{\text {out }} \text { divided by } \\
\text { radiation passing through } A_{\text {in }} \text { of } \mathrm{CPC}[-]\end{array}$ \\
\hline $\begin{array}{ll} & \text { get plane for the heliostats } \\
C_{\mathrm{g}} & \text { geometric ratio of concentration (here: of a }\end{array}$ & $\eta_{\text {itc }}$ & $\begin{array}{l}\text { fraction of radiation through receiver aper- } \\
\text { ture to total radiation on target plane [-] }\end{array}$ \\
\hline СРC) $[-]$ & $\sigma_{\text {mirror }}$ & dispersion of the error distribution of the \\
\hline ratio of flux concentration (here: of a CPC) & & heliostats’ surface [mrad] \\
\hline$[-]$ & $\sigma_{\text {sunshape }}$ & dispersion of sunlight that has the same \\
\hline $\begin{array}{ll}C_{\mathrm{H}}, C_{\mathrm{R}}, & C_{\mathrm{T}} \text { cost of heliostats, receiver and tower } \\
d_{\mathrm{HR}} & \text { distance between heliostat and its aim-point } \\
& \text { on target plane [m] }\end{array}$ & $\sigma_{\text {tot }}$ & $\begin{array}{l}\text { RMS as a measured sunshape [mrad] } \\
\text { dispersion of beam reflected by heliostats } \\
{[\mathrm{mrad}]}\end{array}$ \\
\hline $\begin{array}{l}I_{s} \quad \text { direct normal irradiation }\left[\mathrm{W} / \mathrm{m}^{2}\right] \\
P_{\text {in }}, P_{\text {out }} \text { power at entry }[\mathrm{MW}], \text { respectively outlet }\end{array}$ & $\sigma_{\text {track }}$ & $\begin{array}{l}\text { dispersion of tracking errors of heliostats } \\
\text { [mrad] }\end{array}$ \\
\hline aperture of a CPC $\left[\mathrm{MW}_{\mathrm{CPC}}\right]$ & $\theta$ & design acceptance angle of $\mathrm{CPC}\left[{ }^{\circ}\right]$ \\
\hline $\begin{array}{l}\text { fraction of radiation passing from heliostat } \\
\text { to entry aperture of CPC despite atmo- } \\
\text { spheric attenuation }\end{array}$ & & \\
\hline
\end{tabular}

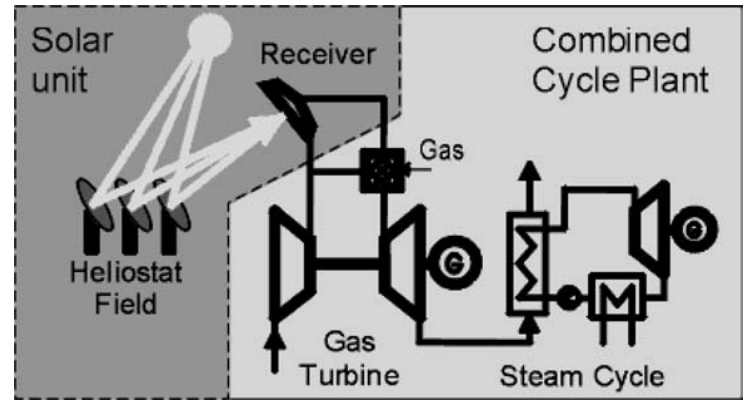

Fig. 1. Scheme of solar powered combined cycle plant.

(Sugarmen et al., 2003), i.e., the Porcupine receiver or the Refos system (Fig. 2). The concentrated radiation passes through a domed window, and is absorbed in a porous absorber, where the heat is transferred to the fluid directly where it is absorbed. The secondary concentrator, which is necessary to increase the concentration, and also serves to protect the front cover of the pressure vessel from the concentrated radiation, is designed to form a rotational compound parabolic concentrator (CPC). In order to approximate a circular entry aperture, while still leaving it capable of forming clusters, a hexagonal entry aperture is chosen. One characteristic of CPCs is that the transmission, as a function of the angle of the incoming radiation varies with the concentration factor (Welford and Winston, 1989): The higher the geometric concentration ratio $C_{\mathrm{g}}$, the more limited is the acceptance angle $\theta$.

$C_{\mathrm{g}}=\frac{A_{\text {in }}}{A_{\text {out }}}=\sin ^{-2} \theta \Longleftrightarrow \theta=\arcsin \left(C_{0}^{-1 / 2}\right)$

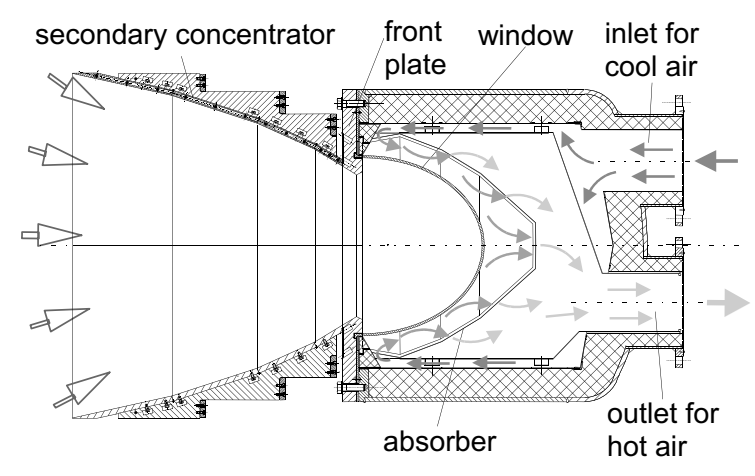

Fig. 2. Section through pressurized receiver with secondary concentrator (Refos-concept).

$C_{\mathrm{g}}$ is a theoretical value. More important is the flux concentration ratio,

$C_{\mathrm{f}}=\frac{P_{\text {out }} / A_{\text {out }}}{P_{\text {in }} / A_{\text {in }}}=C_{\mathrm{g}} \cdot \eta_{\mathrm{CPC}}$

This value includes absorption on the reflective surfaces of the CPC, and the effects of the continuous transmission function (Fig. 3a). In a CRS the view cone resulting from this limited acceptance angle leads to an elliptic, parabolic ${ }^{1}$ or hyperbolic area (Fig. 3b) on the ground, from which the heliostats' power is transmitted through

\footnotetext{
${ }^{1}$ The parabola is the cone section separating the ellipses from the hyperbolas. Hence a parabolic heliostat field boundary occurs, when the CPC's acceptance angle equals the tilt of the CPC's normal; an elliptic area if the tilt is bigger and a hyperbolic if it is smaller.
} 

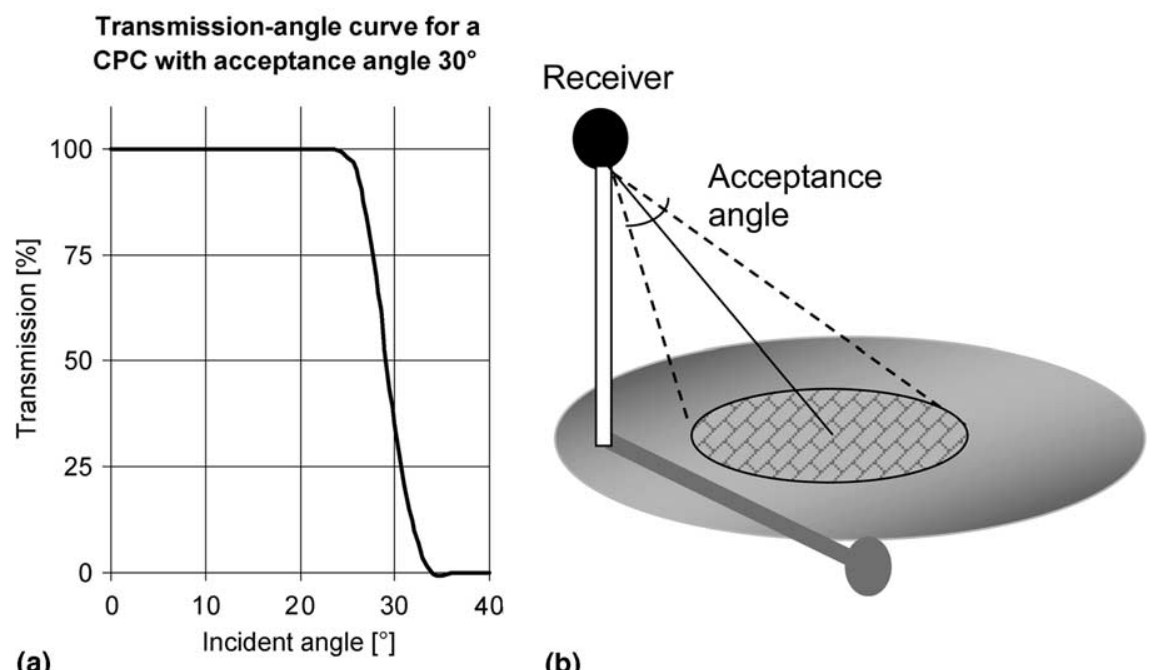

(a)

(b)

Fig. 3. Influence of acceptance angle on transmission factor (Welford and Winston, 1989) (a) and heliostat field (Segal and Epstein, 1999) (b).

the CPC. Radiation from the heliostats outside this area is rejected partly or completely, making much of the ground area near the tower useless for power production. To reach a certain power level in spite of this, high towers are required with corresponding heliostat fields, which extend far in the northern direction. This, however, leads to optical losses in the collector field, as blocking, atmospheric attenuation and spillage are increased. If the area closer to the tower is to be used, additional receiver clusters have to be installed (Fig. 4), which are oriented somewhat to the East and West-or even to the South. This idea has been applied for systems without CPCs in the 1980s (Becker and Böhmer, 1989; Pitman and Vant-Hull, 1986). Segal and Epstein (1999)

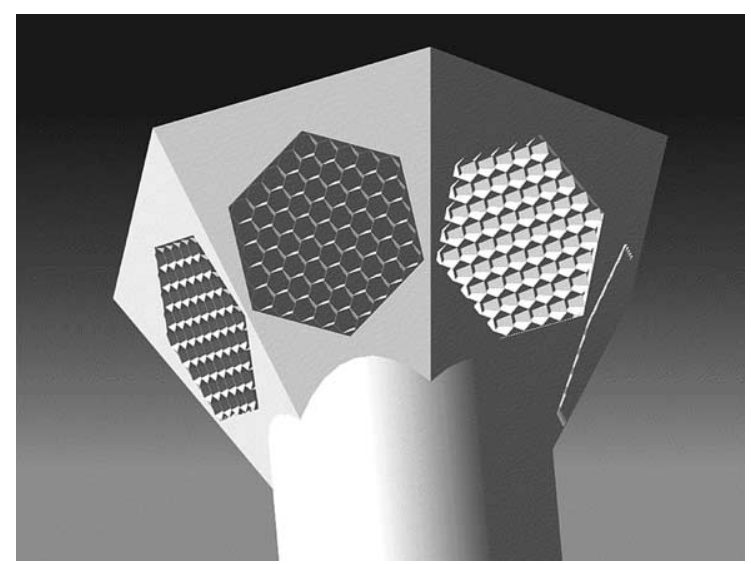

Fig. 4. Illustration of clusters of receivers and their corresponding secondary concentrators. Here four of the six apertures of a MAD configuration can be seen. did consider CPCs, but focused on thermal rather than economic efficiencies. Only two power levels were considered.

The system efficiency of concentrating solar systems is composed of the collector efficiency and the conversion efficiency.

$\eta_{\text {system }}=\eta_{\text {collector }} \cdot \eta_{\text {conversion }}$

Combined cycle processes with their high thermal-toelectric conversion efficiency are the main motivation for the analysis of receivers with secondary concentrators, but they are not the only application: Also some important chemical applications call for similar receiver specifications, i.e., where a pressurized fluid is to be exposed directly to concentrated solar radiation. In order not to limit the scope of this paper to electricity production only the energy collection part of the system is analyzed.

\section{Simulation tool}

\subsection{Requirements}

For this study the simulation tool needs to reproduce all relevant loss mechanisms in CRS, to find out which configuration gives the highest annual yield:

- Cosine loss - quotient of total mirror area and its projected area, as seen from the sun;

- Shading - part of the reflective area that is shadowed by other heliostats or the tower;

- Reflectivity - quotient of reflected energy and energy impinging on the reflective surface; 
- Blocking - fraction of reflected radiation hitting the back of other heliostats;

- Atmospheric attenuation-radiation lost in the air between heliostat field and receiver;

- Spillage-fraction of radiation hitting the target plane, but missing the entry apertures of the CPC clusters;

- CPC transmission losses - energy lost through absorption, and reflection back through the CPC entry aperture.

To perform an approximated annual analysis, a multitude of points in time needs to be considered. To prevent any bias due to a random choice of geometric parameters, such as tower height, heliostat spacing etc., they are optimized through iterative analysis of discrete configurations to find the lowest energy production costs.

HFLCAL (Kiera, 1989), with some extensions by the authors, is able to fulfill the above requirements.

\subsection{Theory behind HFLCAL}

HFLCAL starts off with a large field of hypothetical set of discrete heliostat positions, for each of which the efficiency is calculated. Then the final field is composed by adding up the heliostats performing best on an annual basis until the design power level is reached. For this configuration the annual energy output and the costs are calculated. In optimization runs, this procedure is repeated with changed input parameters. The heliostats' performances are determined as follows.

The heliostat is assumed to be oriented correctly. Tracking errors are merged with the mirror surface errors. Thus, its cosine loss can easily be calculated for a given tower height and sun angles.

Around each heliostat a group of heliostats is checked geometrically for shading and blocking interferences by projecting the mirror outlines onto the planes of their neighbors. In case of a shading analysis the projection follows the rays originating in the sun, to check for blocking in the direction of the reflected rays.

The reflectivity is assumed to be constant over time and includes an average cleanliness factor reduction to account for heliostats, which are out of operation.

The atmospheric attenuation can be calculated simply as a function of the distance between heliostat and receiver $d_{\mathrm{HR}}$ in meters (Leary and Hankins, 1979)

$$
\begin{aligned}
\eta_{\mathrm{aa}}= & 0.99321-0.0001176 \cdot d_{\mathrm{HR}}+1.97 \cdot 10 E-8 \cdot d_{\mathrm{HR}}^{2} \\
& \left(d_{\mathrm{HR}} \leqslant 1000 \mathrm{~m}\right)
\end{aligned}
$$

This formula was extended for the range above $1 \mathrm{~km}$ to give realistic results for larger slant ranges:

$\eta_{\mathrm{aa}}=\mathrm{e}^{-.0001106 \cdot d_{\mathrm{HR}}} \quad\left(d_{\mathrm{HR}}>1000 \mathrm{~m}\right)$
These formulae agree well with the model of Pitman and Vant-Hull (1982) for a visual range of about $40 \mathrm{~km}$.

To calculate the spillage, the flux distribution in the plane of the secondary concentrator entry apertures has to be known. HFLCAL assumes the flux distribution of each heliostat ${ }^{2}$ to be circular Gaussian, which is justified by the Central Limit Theorem stating that the convolution of two or more distribution functions (here: sunshape and mirror surface errors) converges towards a Gaussian distribution, especially if one of the original distributions already is Gaussian, which is the case here (the mirror surface errors). According to Rabl (1985) the dispersion of the flux distribution can be calculated as

$\sigma_{\text {tot }}=\left(\sigma_{\text {sunshape }}^{2}+\sigma_{\text {mirror }}^{2}+\left(2 \cdot \sigma_{\text {track }}\right)^{2}\right)^{0.5}$

That means, that the sunshape is entered implicitly only. According to DLR sunshape measurements (Neumann et al., 2002), a narrow sunshape with a $\sigma_{\text {sunshape }}$ of $2.09 \mathrm{mrad}$ can be used independent of the DNI. Now the part of the heliostat's flux distribution that lies within the boundaries of the receiver can be integrated, resulting in the intercepted fraction $\eta_{\text {itc }}$ of power.

$\eta_{\text {itc }}=\frac{1}{2 \pi \cdot \sigma_{\text {tot }}^{2}} \int_{(x)} \int_{(y)} \exp \left(-\frac{x^{2}+y^{2}}{2 \cdot \sigma_{\text {tot }}^{2}}\right) \mathrm{d} y \cdot \mathrm{d} x$

The fraction outside of the receiver boundaries $\left(1-\eta_{\text {itc }}\right)$ is called spillage. The amount of spilled radiation strongly depends on the aiming strategy, i.e., on where each heliostat's aim point is located on the receiver plane. The closer the target point is set towards the edge of the receiver, the higher the loss. In a realistic operation scenario such a spread distribution would be necessary, however, to prevent destructively high fluxes at the center, and uselessly low radiation concentrations near the edges. The required multiaiming strategies are quite sophisticated and so in this study all heliostats are aimed onto the receiver center. Thus, the calculated spillage is a lower boundary.

The transmission losses in the CPC are calculated by interpolating in ray-tracing generated tables of transmission factors for various entry angles. HFLCAL can either generate these transmission tables itself for a given acceptance angle and truncation length, or it can use tables that are generated by more specialized ray-tracing codes, such as SORSIM.

Receiver losses (due to reflection and radiation) were left out of this study, as they depend on the amount of radiation in each receiver module, i.e., the flux distribu-

\footnotetext{
${ }^{2}$ HFLCAL assumes only one Gaussian distribution per heliostat. Facets are only considered by diluting this distribution in off-axis constellations to account for astigmatic effects due to facet canting.
} 
tion in the aperture plane, which is, as explained above, not considered in this simplified approach.

Power conversion losses were not considered either.

All the relevant effects are calculated for each heliostat at every full hour of one day (here: the 21st) of each month. By multiplying the hourly results by the number of days in the respective month and adding this up, a good estimate of an annual radiative energy yield (at the interface between secondary concentrator and receiver entry) and average losses are obtained.

The figure of merit, which is used to compare different system layouts, is the cost of capital of the investment for the solar components (heliostats, secondary concentrator, receiver, and tower) divided by the annual energy (at said interface) in a cloudless year. This figure will be called "concentration cost". For systems that do not vary but in the dimension of certain components, this is a fair basis for comparison. Operations and maintenance costs, e.g., cleaning the mirrors, were neglected, as they very strongly depend on the site.

\subsection{Validation}

HFLCAL was compared with the ray-tracing tool MIRVAL (Leary and Hankins, 1979) to verify that the errors made by different shading and blocking algorithms and the assumption, that each heliostat's flux is normally distributed, are of an acceptable magnitude.

Main goal is a correct estimate of the energy intercepted by the receiver. Fig. 5 shows a comparison of the loss mechanisms as they are calculated by the two tools. The results agree very well. A similar congruence can be observed in other cases, too, even though the par- tial efficiencies do not always compensate each other as they did in this case, with the total efficiency agreeing to a very high degree.

\subsection{Model used for this study}

The following assumptions were made:

- Environment: Cloudless year, visual range $40 \mathrm{~km}$, sealevel, narrow sun-shape, unobstructed horizon, flat land, no land cost.

- Heliostat: Sanlucar 120 (based on the Sanlucar 90 heliostat (Mancini, 2000), but with four instead of three facet columns); perfectly focused on respective receiver center point; reflectivity $\times$ cleanliness $\times$ availability $=0.87$; specific heliostat field cost including: engineering, production, transport, erection, power supply and communication, start-up tests: $C_{\mathrm{H}}=120 € / \mathrm{m}^{2}$. Power supply and communication are assumed to shift from a wire solution to one utilizing PV and radio control for larger fields. This leads to connection costs that are independent of the heliostat spacing.

- Tower: Cost function $C_{\mathrm{T}}=410,000 € \cdot \exp \left(0.011 \cdot h_{\mathrm{T}}\right)$, $h_{\mathrm{T}}$ in [m].

- Receiver: Refos including secondary concentrator $C_{\mathrm{R}}=27,300 € / \mathrm{m}^{2}$ (based on $A_{\text {in }}(!)$ ); cylindrical receiver (Jones, 2003) $C_{\mathrm{R}}=42,400 € / \mathrm{m}^{2}$ (based on absorber area).

- Secondary concentrator: Its geometry is based on the Refos-concept, i.e., the exit aperture fits snugly into the Refos-pressure window ( $30 \mathrm{~cm}$ radius). The largest possible acceptance angle can be calculated by

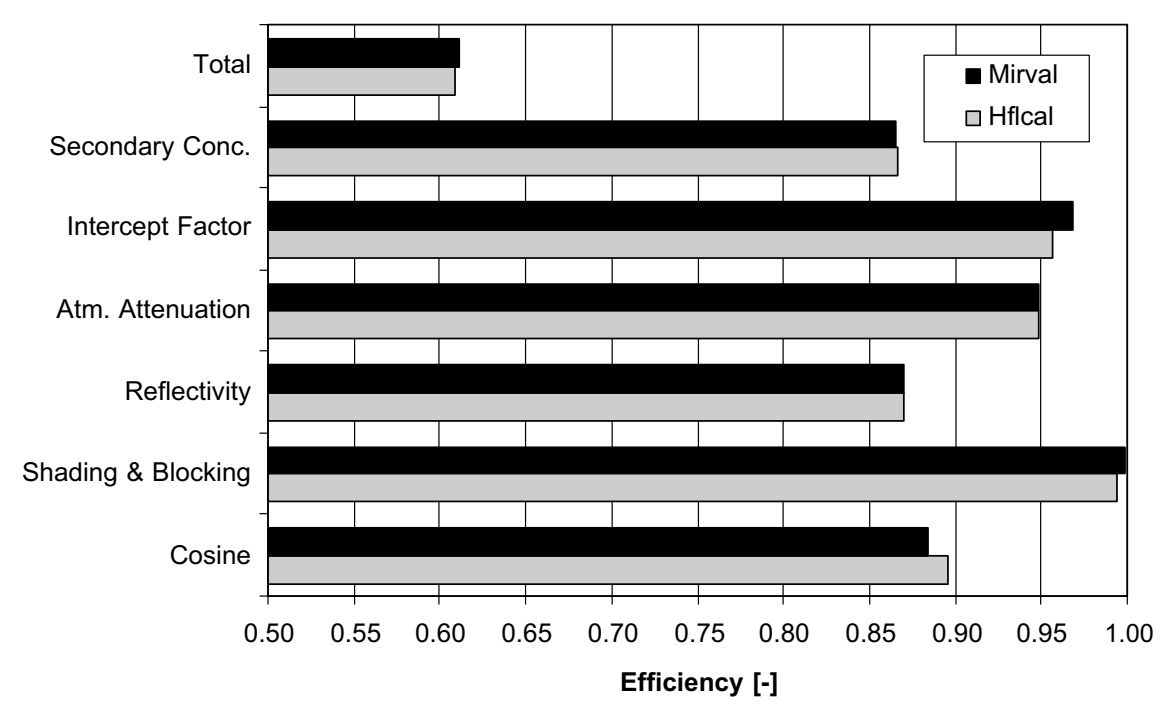

Fig. 5. Comparison of loss mechanisms as calculated by HFLCAL and MIRVAL. The underlying example is the southern sub-field of a $200 \mathrm{MW}_{\mathrm{CPC}}$ plant situated at $20^{\circ} \mathrm{N}$. The analyzed point of time is noon on June 21 st. The biggest difference occurs in the calculation of the cosine $\left(\left|\Delta \eta_{\cos }\right|=1.3 \%\right)$ and intercept factor $\left(\left|\Delta \eta_{\cos }\right|=1.1 \%\right)$. The difference in the total optical efficiency is $0.2 \%$. 
considering the smallest possible concentration, resulting from the ratio of the total area covered by the cluster in the tightest packing of the pressure vessels, to the sum of the window aperture areas. This leads to a minimal concentration of about 4 and thus to an acceptance angle of about $\theta=30^{\circ}$. Further concentration would yield a lower CPC-transmission factor and a smaller acceptance angle. The following data was assumed: reflectivity $90 \%$, geometric concentration of 4.24, the costs are included in the receiver costs.

All cost functions are based on the year 2004 .

In order to gain some insight into the influence of the geographic latitude two cases were considered: $20^{\circ} \mathrm{N}$ and $40^{\circ} \mathrm{N}$. They represent the southernmost and the northernmost latitude of likely commercial sites on the northern hemisphere. Interpreting the results, it has to be kept in mind, that the more southern site has a higher annual DNI $\left(2716 \mathrm{~kW} \mathrm{~h} / \mathrm{m}^{2}\right.$ instead of $2542 \mathrm{~kW} \mathrm{~h} / \mathrm{m}^{2}$ ).

To analyze the influence of multiple aperture designs (MAD), a single North-oriented heliostat field (single aperture design, SAD) was compared with one split into six sub-fields, each associated with one aperture. The apertures were defined to face North $\left(0^{\circ}\right), \pm 60^{\circ}, \pm 120^{\circ}$, and South $\left(180^{\circ}\right)$.

The power fractions at design point (June 21st, noon) of the sub-fields were assumed (by referencing an optimized surround field around a cylindrical receiver) to be distributed according to Fig. 6 .

Then a genetic algorithm optimizer varied three heliostat distribution parameters, tower height, size

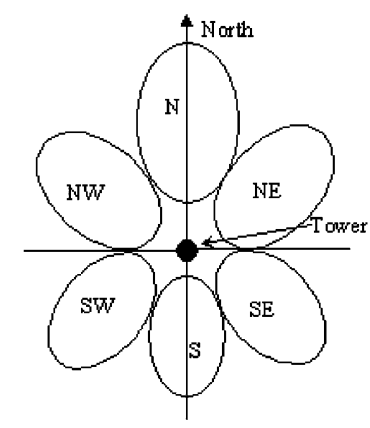

\begin{tabular}{|l|l|l|l|l|}
\hline & \multicolumn{4}{|c|}{ Power fraction } \\
in sub-field \\
\hline Latitude & N & $\begin{array}{l}\text { NE } \\
\text { NW }\end{array}$ & $\begin{array}{l}\text { SE } \\
\text { SW }\end{array}$ & S \\
\hline $\mathbf{2 0}^{\circ} \mathrm{N}$ & 21 & 18 & 15 & 13 \\
\hline $\mathbf{4 0}^{\circ} \mathrm{N}$ & 22 & 19 & 14 & 12 \\
& & & & \\
\hline
\end{tabular}

Fig. 6. Power fractions [\%] from sub-fields of MAD at latitudes $20^{\circ}$ and $40^{\circ}$. and tilt angle of the receiver. This leads to some system configurations that are unable to deliver sufficient power. These sets of parameters will be penalized during the optimization. The genetic algorithm is blind to what leads to the failure, but in avoiding the unsuccessful combination in the further course of optimization it is able to "learn".

As a reference for the $20^{\circ} \mathrm{N}$-case, a surround field, concentrating the sunlight onto a cylindrical receiver (without secondary concentrator), was analyzed, assuming equal cost parameters except for the receiver cost. The power level is given by the amount of power intercepted - but not absorbed - by the cylindrical receiver. A utility study (Hillesland and Weber, 1990) showed a similar performance at slightly higher costs for systems with cavity receivers. For that reason only the cylindrical receiver is analyzed as a reference.

\section{Results}

When aiming at the commercialization of solar power plants, it is very important to know the optimal power level. Thus, the power reaching the receiver (from the CPC exit) at design point (June 21st, noon) is varied between 10 and $400 \mathrm{MW}_{\mathrm{CPC}}$.

Fig. $7 \mathrm{a}$ and $\mathrm{b}$ illustrates how far the SAD heliostat field associated extends North at a medium and a high power level. The further away a heliostat is located from the receiver, the more the losses due to atmospheric attenuation and spillage increase. Therefore, the SAD systems have optimal tower heights that are about $30 \%$ higher than for the MAD systems, to allow for a tighter packing of the heliostats without increasing blocking effects.

The last row of heliostats in the SAD configuration has a low efficiency. The heliostats in the southerly field of MAD layout, suffer higher cosine losses, but are in most cases superior overall.

At $20^{\circ} \mathrm{N}$ the efficiencies can be gathered from Table 1 . It can be seen, that the worst heliostat of a $50-\mathrm{MW}_{\mathrm{CPC}}$ plant installed in the southern field is $12 \%$ more costeffective than one of the last row in the SAD field. For the $400-\mathrm{MW}_{\mathrm{CPC}}$ plant at the same latitude the worst heliostat installed in the southern field is $57 \%$ more cost-effective than one added to the northern field.

At $40^{\circ} \mathrm{N}$ the cosine efficiency in the North increases and decreases in the South. The overall efficiency of the worst MAD heliostat of the $50-\mathrm{MW}_{\mathrm{CPC}}$ plant is equal to the efficiency of the worst heliostat associated with the SAD system, but the $400-\mathrm{MW}_{\mathrm{CPC}}$ plant again has an advantage of $41 \%$ for the MAD heliostats (Table 2).

SAD and MAD (and at $20^{\circ} \mathrm{N}$ the surround field) were compared for a wide range of power levels - from 10 to $800 \mathrm{MW}_{\mathrm{CPC}}$. Fig. 8 shows relative concentration 

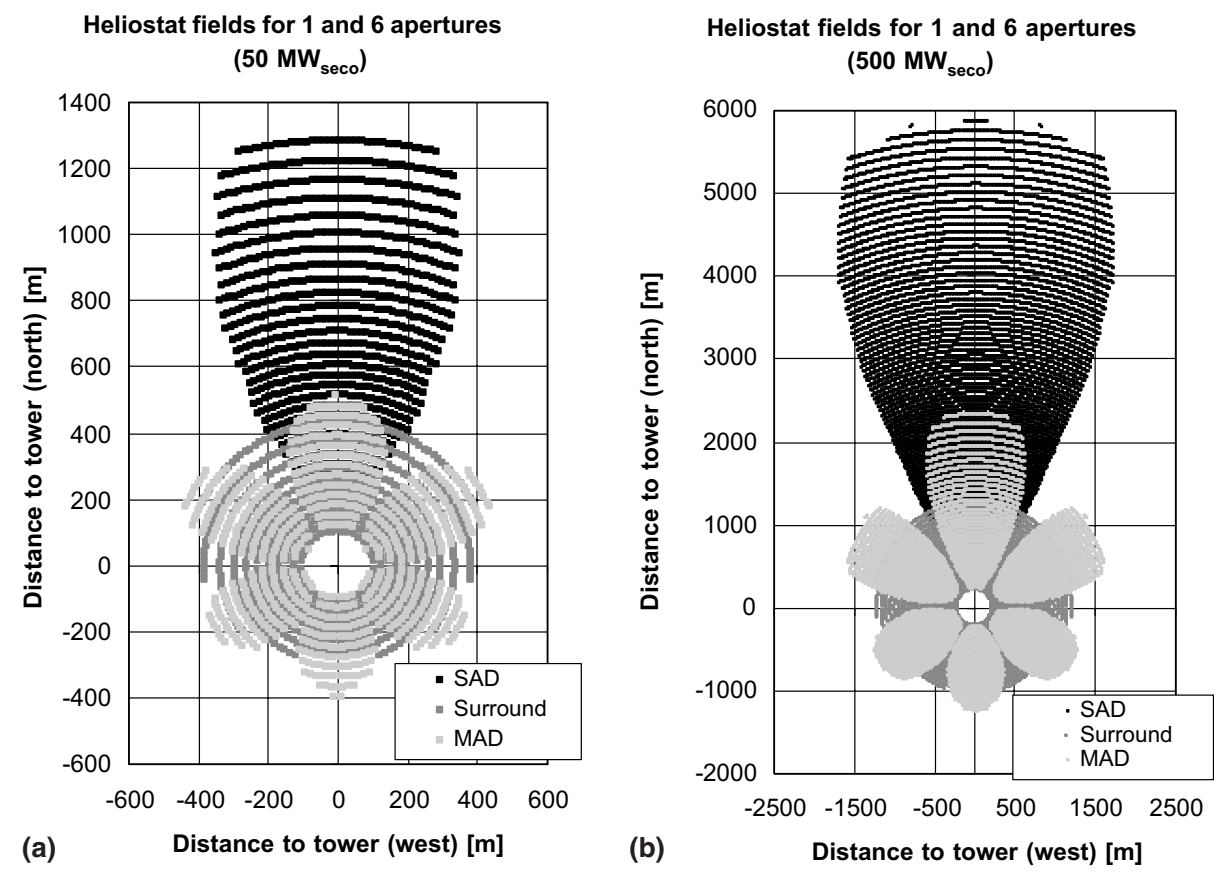

Fig. 7. (a) and (b) Heliostat fields for medium and high power levels.

Table 1

Yearly average efficiencies for $20^{\circ} \mathrm{N}, 50-\mathrm{MW}_{\mathrm{CPC}}$ and $400-\mathrm{MW}_{\mathrm{CPC}}$ plant

\begin{tabular}{|c|c|c|c|c|c|c|}
\hline \multirow[t]{2}{*}{ Efficiencies } & \multicolumn{3}{|l|}{$50 \mathrm{MW}_{\mathrm{CPC}}$} & \multicolumn{3}{|c|}{$\underline{400 \mathrm{MW}_{\mathrm{CPC}}}$} \\
\hline & $\begin{array}{l}\text { Last row, } \\
\text { SAD }\end{array}$ & $\begin{array}{l}\text { Southernmost } \\
\text { heliostat MAD }\end{array}$ & Factor & $\begin{array}{l}\text { Last row, } \\
\text { SAD }\end{array}$ & $\begin{array}{l}\text { Southernmost } \\
\text { heliostat MAD }\end{array}$ & Factor \\
\hline Cosine & $80 \%$ & $75 \%$ & 0.94 & $79 \%$ & $71 \%$ & 0.90 \\
\hline Shading \& Blocking & $90 \%$ & $90 \%$ & 1.05 & $84 \%$ & $88 \%$ & 1.05 \\
\hline Atmospheric Transmission & $87 \%$ & $96 \%$ & 1.10 & $62 \%$ & $91 \%$ & 1.47 \\
\hline Intercept & $65 \%$ & $74 \%$ & 1.14 & $63 \%$ & $76 \%$ & 1.21 \\
\hline Secondary Concentrator & $91 \%$ & $89 \%$ & 0.98 & $91 \%$ & $89 \%$ & 0.98 \\
\hline Total (including reflectivity) & $33 \%$ & $37 \%$ & 1.12 & $21 \%$ & $33 \%$ & 1.57 \\
\hline
\end{tabular}

$\operatorname{cost}^{3}$ vs. the power level. The costs of a 10-MW $\mathrm{CPC}_{\mathrm{CAD}}$ plant at $40^{\circ} \mathrm{N}$ (a probable size, configuration and location of a future demonstration plant) is defined as $100 \%$. The rest of the data is scaled accordingly. Graphs for $20^{\circ} \mathrm{N}$ are shown as grey lines $\left(40^{\circ} \mathrm{N}\right.$ black); graphs for MAD heliostat fields are dotted (SAD — solid line, surround field - dashed line).

The results can be summarized as follows (if no latitude is mentioned, the statement is true for both analyzed latitudes):

\footnotetext{
${ }^{3}$ These costs are not electricity generation cost, as receiver and power cycle efficiency as well as O\&M costs are neglected. See "model" chapter for detailed description of the assumptions.
}

- The higher the power level, the greater is the advantage of MAD.

- Optimal power level is about $50-400 \mathrm{MW}_{\mathrm{CPC}}$ for MAD and 25-50 $\mathrm{MW}_{\mathrm{CPC}}$ for SAD.

- For MAD, the cost efficiency is greater at $20^{\circ} \mathrm{N}$ than at $40^{\circ} \mathrm{N}$; for SAD, too, but only slightly.

- The optimal power level of CRS without secondary is higher than for systems using secondary concentrators $\left(\geqslant 400 \mathrm{MW}_{\mathrm{CPC}}\right)$.

- The CRS with secondary concentrator are less cost efficient than those having a surround field (powercycle and storage efficiency may however change this).

Regarding the average annual concentration efficiency (including secondary concentrator) vs. the power level (Fig. 9) the following results can be derived: 
Table 2

Yearly average efficiencies for $40^{\circ} \mathrm{N}, 50-\mathrm{MW}_{\mathrm{CPC}}$ and $400-\mathrm{MW}_{\mathrm{CPC}}$ plant

\begin{tabular}{|c|c|c|c|c|c|c|}
\hline \multirow[t]{2}{*}{ Efficiencies } & \multicolumn{3}{|l|}{$50 \mathrm{MW}_{\mathrm{CPC}}$} & \multicolumn{3}{|c|}{$400 \mathrm{MW}_{\mathrm{CPC}}$} \\
\hline & $\begin{array}{l}\text { Last row, } \\
\text { SAD }\end{array}$ & $\begin{array}{l}\text { Southernmost } \\
\text { heliostat MAD }\end{array}$ & Factor & $\begin{array}{l}\text { Last row, } \\
\text { SAD }\end{array}$ & $\begin{array}{l}\text { Southernmost } \\
\text { heliostat MAD }\end{array}$ & Factor \\
\hline Cosine & $85 \%$ & $68 \%$ & 0.80 & $84 \%$ & $63 \%$ & 0.75 \\
\hline Shading \& Blocking & $88 \%$ & $93 \%$ & 1.06 & $85 \%$ & $90 \%$ & 1.06 \\
\hline Atmospheric Transmission & $88 \%$ & $96 \%$ & 1.09 & $62 \%$ & $91 \%$ & 1.47 \\
\hline Intercept & $66 \%$ & $74 \%$ & 1.12 & $62 \%$ & $77 \%$ & 1.24 \\
\hline Secondary Concentrator & $91 \%$ & $89 \%$ & 0.98 & $91 \%$ & $90 \%$ & 0.99 \\
\hline Total (including reflectivity) & $35 \%$ & $35 \%$ & 1.00 & $22 \%$ & $31 \%$ & 1.41 \\
\hline
\end{tabular}

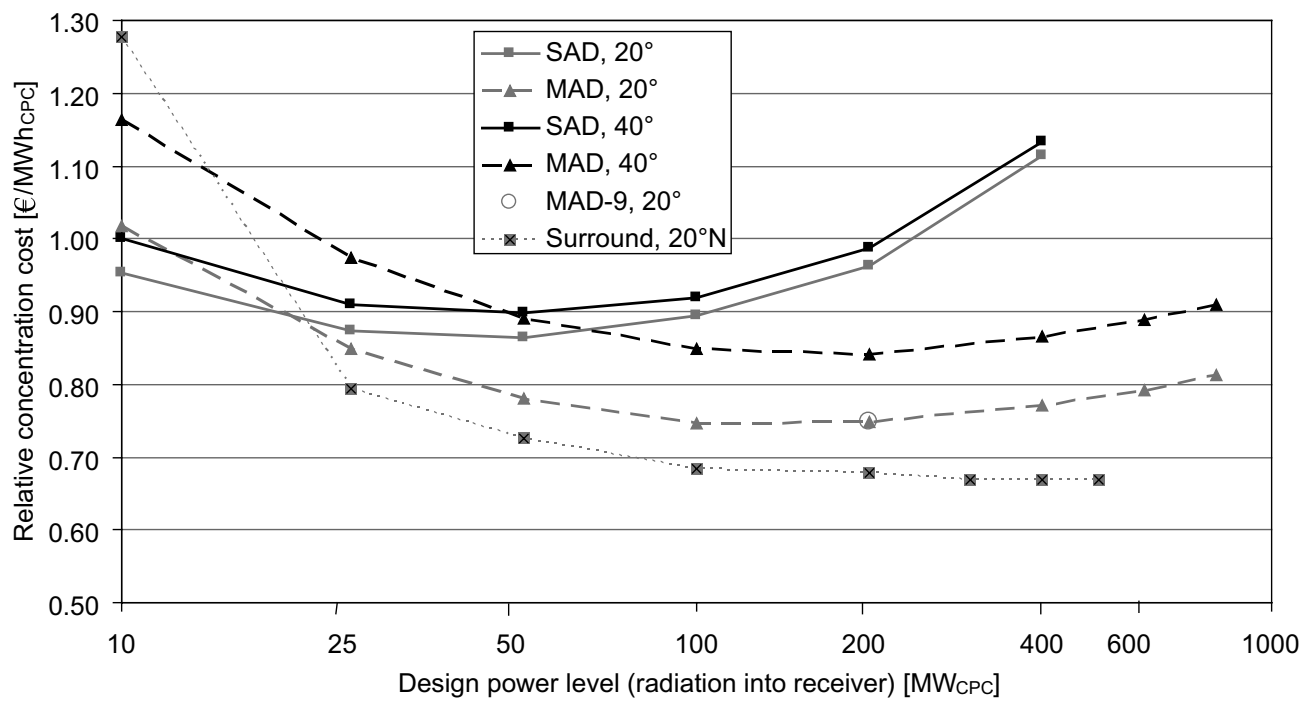

Fig. 8. Concentration cost vs. plant size (relative to the SAD $10 \mathrm{MW}_{\mathrm{CPC}}, 40^{\circ} \mathrm{N}$ case).

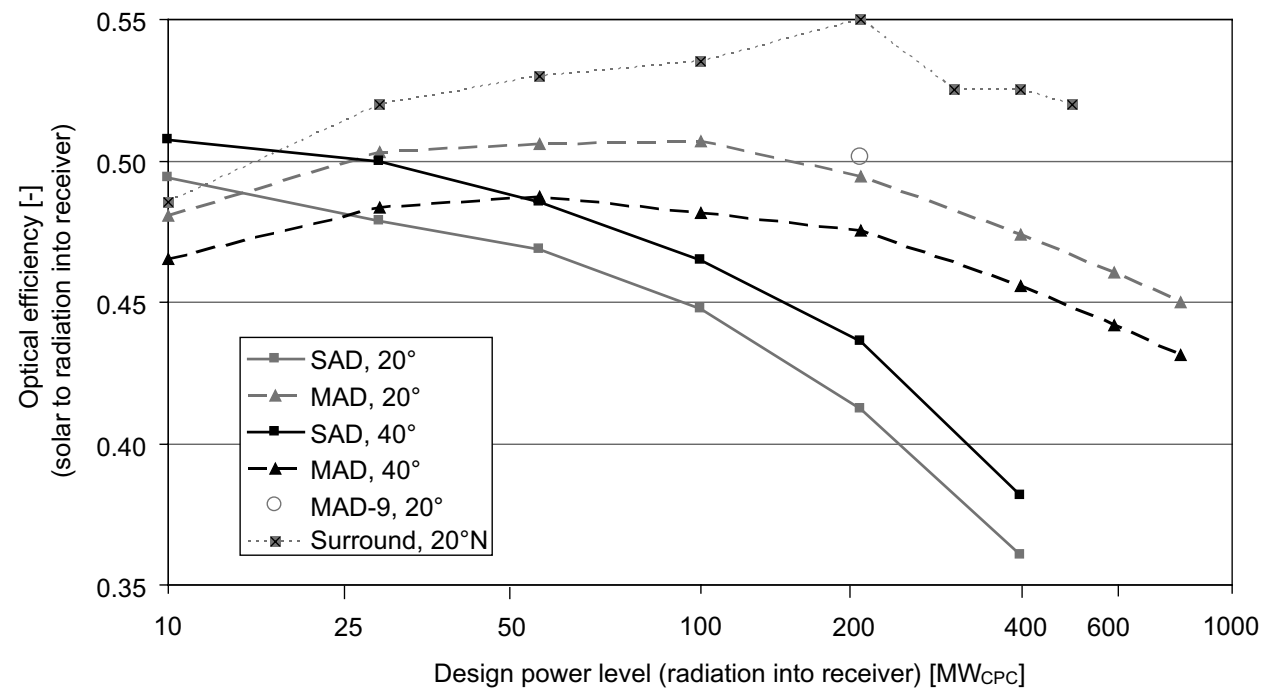

Fig. 9. Annual concentration efficiency vs. plant size. 


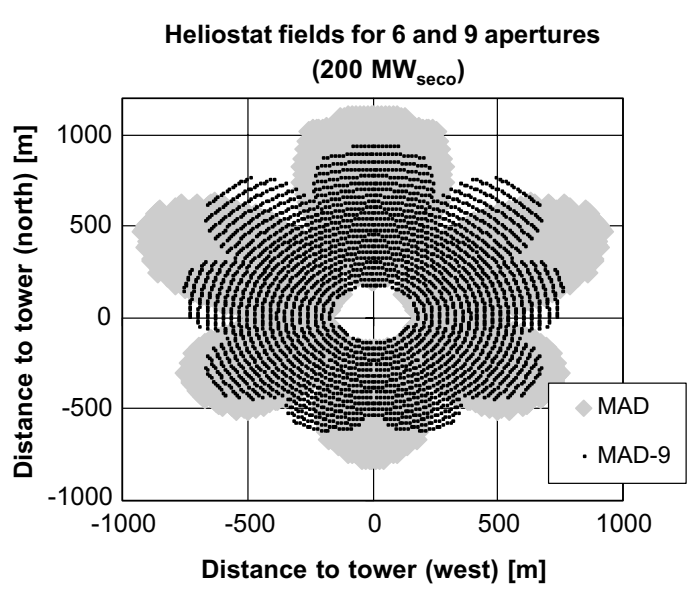

Fig. 10. Heliostat fields for 6 and 9 receiver apertures.

- With rising power levels the efficiency decreases faster for SAD than for MAD.

- Due to the cosine loss, the efficiency of the SAD is better at higher latitudes.

- For MAD the cosine loss of the southern sub-field leads to higher efficiencies at latitudes closer to the equator.

- The optical efficiency of surround fields is higher, as there are no CPC-transmission losses and all good heliostat locations near the tower can be used.

- The decrease of the concentration efficiency with rising power levels is not as distinctive for the surround field as it is for systems with secondary concentrators.

It is obvious from Fig. 7a and b, that the MAD heliostat fields, with one sub-field being tangent to the next, cannot make use of many heliostats outside the view cone of the secondary concentrators, which would have otherwise been quite efficient. Increasing the number of apertures (MAD-9) and consequently overlapping view cones (Fig. 10) lead to a slightly better performance, but require larger receiver areas, which counteract that advantage, when regarding costs (see Figs. 9 and 10).

That means CRS with secondary concentrators are only competitive if either the higher efficiency of combined-cycle power conversion units recover the optical losses, or if their optics can be further improved, e.g., through better secondary concentrators or beam-down optics (Segal and Epstein, 1999).

\section{Sensitivity}

In order to see how sensitive the concentration cost react on variation of the assumed component cost parameters, they were varied by $\pm 30 \%$ (Fig. 11). As can be expected, a change of heliostat costs, which make up the major part of the investment costs, yields the most significant change in concentration cost.

\section{Example}

In central Spain a $50-\mathrm{MW}_{\mathrm{e}}$ combined-cycle plant, with an efficiency of $45 \%$, is to be driven by a solar field. At full solar input (June 21st, noon) 25\% thermal power are added through fuel combustion. The efficiency of the receiver (without secondary concentrator) is assumed to be $92 \%$.

Thus, the heliostat field has to deliver (at CPC outlet) $P_{\text {out }}=(50 / .45) \cdot(1-.25) / .92=91 \mathrm{MW}_{\mathrm{CPC}}$

The electricity cost of the solar components can be extracted from Fig. 8: Central Spain is close to the $40^{\circ} \mathrm{N}$ case; $91 \mathrm{MW}_{\mathrm{CPC}}$ can be interpolated between the

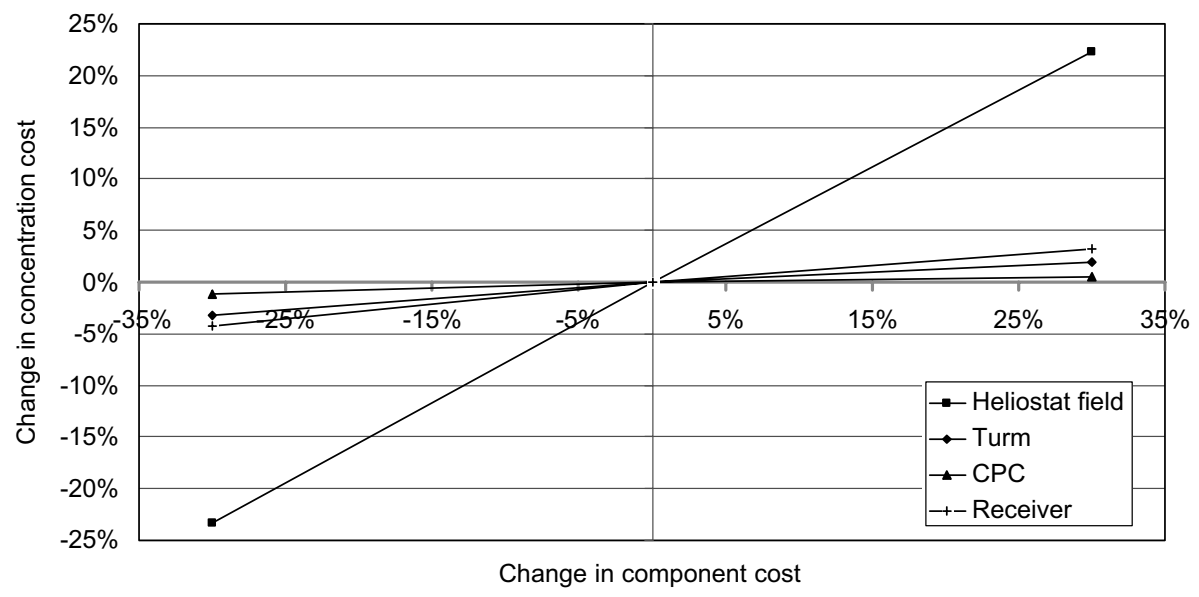

Fig. 11. Sensitivity of concentration cost due to change of component costs of $\pm 30 \%$. 
$50 \mathrm{MW}_{\mathrm{CPC}}$ and the $100 \mathrm{MW}_{\mathrm{CPC}}$ point. It can be seen that in this case the SAD leads similar costs as the MAD (both about $80 \%$ of a SAD demo plant). Those results being so close to each other, the decision would probably depend on other facts than cost, such as maintainability, simplicity of construction, etc. The same plant in southern Egypt $\left(23^{\circ} \mathrm{N}\right)$ would clearly call for a MAD $(\approx 70 \%)$ instead of a SAD $(\approx 80 \%)$.

Such a plant would have a tower of about $170 \mathrm{~m}$ height $\left(40^{\circ} \mathrm{N}\right)$ or $210 \mathrm{~m}\left(20^{\circ} \mathrm{N}\right)$. The total aperture area is $280 \mathrm{~m}^{2}$ or $240 \mathrm{~m}^{2}$, respectively, which leads to a flux density concentration ratio (at design point $\left(I_{s}=877 \mathrm{~W} / \mathrm{m}^{2}\right)$, after the secondary concentrator with $\left.C_{\mathrm{g}}=4.24\right)$ of about 1300 or 1600 , respectively.

\section{Conclusion}

As central receiver systems with secondary concentrators will reach a state beyond research plants, i.e., power levels of $30 \mathrm{MW}_{\mathrm{CPC}}$ and more, they will have to make use of multiple-aperture design, so that the investment for the tower can be used by more than one heliostat field. Optimal power levels of such power plants have been calculated to range between 100 and $400 \mathrm{MW}_{\mathrm{CPC}}$, which amounts to $50-200 \mathrm{MW}_{\mathrm{e}}$. When considering entire power plants, i.e., including the power block, the optimum power level will shift slightly towards bigger plants due to economy of scale.

\section{References}

Becker, M., Böhmer, M. (Eds.), 1989. GAST - the Gas-cooled Solar Tower Technology Program, Proceedings of the Final Presentation. Springer, Berlin.

Buck, R., Lüpfert, E., Tellez, F., 2000. Receiver for solar hybrid gas turbine and CC systems (REFOS). In: IEA Solar Thermal 2000 International Conference, 8-10 March 2000, Sydney, Australia. pp. 95-100.
Hillesland, T., Weber, E.R., 1990. Utilities' study of solar central receivers. In: Gutpa, B.P., Traugott, W.H. (Eds.), Solar Thermal Technology-research Development and Applications, Proc. 4th Int. Symp., Santa Fe NM. Hemisphere Publishing Corporation, New York, pp. 165-176.

Jones, S., 2003. Avenues for cost reduction of molten salt solar power tower plants. In: ISES Solar World Congress, 14-19 June 2003, Göteborg, Sweden.

Karni, J., Kribus, A., Rubin, R., Sagie, D., Doron, P., Fiterman, A., 1997. The DIAPR: a high-pressure, high-temperature solar receiver. Transactions of ASME 119, 74-78.

Kiera, M., 1989. Heliostat field: computer codes, requirements, comparison of methods. In: Becker, M., Böhmer, M. (Eds.), GAST-proceedings of the Final Presentation. Springer, Berlin, pp. 95-113.

Leary, P.L., Hankins, J.D., 1979. A User's Guide for MIRVAL - a computer code for comparing designs of heliostatreceiver optics for central receiver solar power plants. Sandia Laboratories Report, SAND77-8280, p. 14.

Mancini, T., 2000. Catalog of heliostats. Solar PACES Technical Report No. III-1/00.

Neumann, A., Witzke, A., Jones, S., Schmitt, G., 2002. Representative terrestrial solar brightness profiles. Journal of Solar Energy Engineering 124 (2), 198-204.

Pitman, C.L., Vant-Hull, L.L., 1982. Atmospheric transmittance model for a solar beam propagating between a heliostat and a receiver. ASES Progress in Solar Energy, 1247-1251.

Pitman, C.L., Vant-Hull, L.L., 1986. Performance of optimized solar central receiver systems as a function of receiver thermal loss per unit area. Solar Energy 37, 457-468.

Rabl, A., 1985. Active Solar Concentrators and Their Applications. Oxford University Press, New York.

Segal, A., Epstein, M., 1999. Comparative performances of 'tower-top' and 'tower-reflector' central solar receivers. Solar Energy 65, 207-226.

Sugarmen, C., Ring, A., Buck, R., Heller, P., Schwarzbözl, P., Tellez, F., Marcos, M.J., Enrile, J., 2003. Solar-hybrid gas turbine power plants - test results and market perspective. In: ISES Solar World Congress, 14-19 June 2003, Göteborg, Sweden.

Welford, W.T., Winston, R., 1989. High Collection Nonimaging Optics. Academic Press, San Diego, pp. 55-72. 